\title{
Health insurance subscription among women in reproductive age in Ghana: do socio-demographics matter?
}

\author{
Hubert Amu* (D) and Kwamena Sekyi Dickson
}

\begin{abstract}
Background: Premised that health insurance schemes in Africa have only been introduced recently and continue evolving, various concerns have been raised regarding their effectiveness in improving utilisation of orthodox health care and the reduction of out-of-pocket expenditures for their population, particularly women.

Objective: To examine the effects of socio-demographics on health insurance subscription among women in Ghana.

Methods: The study draws on the 2014 Ghana Demographic and Health Survey. Bivariate descriptive analysis and binary logistic regression were used to analyse the data.

Results: Wealth status, age, religion, birth parity, marriage and ecological zone were found to have significantly predicted health insurance subscription among women in reproductive age in Ghana. Urban dwellers, women who are nulliparous, those with no or low levels of education, African traditionalists and the poor were those who largely did not subscribe to the scheme.

Conclusion: The findings underscore the need for the National Health Insurance Authority to carry out more education in association with the National Commission for Civic Education and the Information Services Department to recruit more urban dwellers, nulliparous women, those with no or low levels of education, African traditionalists and the poor unto the scheme.
\end{abstract}

Keywords: Ghana, Health insurance, Subscription, Women, Socio-demographics, Out-of-pocket payments

\section{Background}

A major issue that continues to be of principal prominence in most countries across the globe entails the capacity of their health financing structures to provide adequate financial risk safeguard to all of their population against the costs of health care as they strive to achieve universal health coverage $[1,2]$. In developing countries, health care accessibility remains limited as a result of financial and socio-cultural challenges. Out-ofpocket payments are among the main factors which prevent majority of the people in these countries from accessing timely health care [3]. This sometimes results in circumstances whereby enormous financial hurdles come upon entire countries through higher spending on treatment of ailments [4].

\footnotetext{
* Correspondence: hubertamu@gmail.com

Department of Population and Health, University of Cape Coast, Cape Coast, Ghana
}

Out-of-pocket payments constitute a strong barrier to the utilisation of health care services, as well as precluding adherence to long term treatment especially among the vulnerable and poor [5]. Out-of-pocket payments for health care at the point of service delivery have also been troubling for the economic disposition of the poor, therefore, causing serious challenges with regards to essential daily needs as their incomes are drained by health care spending [6]. In order to substitute the user fees approach to health care financing and hence ameliorating the exorbitant health care cost for the masses, all member States of the World Health Organisation (WHO) adopted a resolution which aimed at encouraging nations to develop health financing systems with the aim of providing universal coverage [7]. One major approach to adequate health financing for many of these countries in efforts to achieve universal health coverage has 
therefore become health insurance [8]. There has been considerable interest in exploring the capabilities of health insurance in Africa, a continent which is considered to have a strong propensity for risk sharing across populations and time [9]. A number of African countries (Rwanda, Nigeria, Tanzania, Kenya and Ghana) are thus currently experimenting with various health insurance options which comprise both private and public schemes [10-14].

Premised that the health insurance schemes in Africa have been introduced within the last four decades and continue evolving, various concerns have been raised regarding their effectiveness in the reduction of out-ofpocket expenditures for their populations and improving utilisation of orthodox health care; a system in which health care professionals treat diseases and symptoms using radiation, drugs or surgery [15]. Access to effective health insurance has been noted to affect households by leading to better health especially among women who constantly need maternal and child health services as well as mitigating the risk of health shocks and reducing out-of-pocket health expenses [16, 17]. It is therefore imperative to understand the various factors which affect the ability of people, particularly women in their reproductive age to subscribe to health insurance.

Even though Ghana's National Health Insurance Scheme (NHIS) became operational in 2003 through the National Health Insurance Law (Act 650 of Parliament), the scheme had a legal framework in 2004 through the National Health Insurance Regulations (L.I. 1809) [18, 19]. Financing of the NHIS is done by a $2.5 \%$ insurance levy as Valued Added Tax (VAT) on goods and services, $2.5 \%$ deductions from pension contributions of workers in the formal sector with the Social Security and National Insurance Trust (SSNIT) and yearly premiums paid by adults (persons eighteen years of age and above) [20]. The scheme is also financed through monies allocated to the Health Insurance Fund (HIF) by the legislature in addition to grants, investments, donations, voluntary contributions and gifts [21]. SSNIT pensioners, persons who are seventy years and above, children under the age of eighteen years and pregnant women, however, constitute exemptions on the NHIS from payment of yearly premium [20].

The National Health Insurance Scheme covers about $95 \%$ of the disease burden of Ghana. These comprise services provided for out-patient clients such as diagnostic testing and operations including repair of hernia; most services for in-patient clients which include care by specialists, majority of surgeries and accommodation at the wards of health facilities; treatments for oral health; services related to maternal care including caesarean sections; emergency care; and all drugs that are listed on the medicines list of the National Health Insurance Scheme [22].
The institution mandated by law to manage the National Health Insurance Scheme is the National Health Insurance Authority (NHIA). The NHIA, in efforts to improve the scheme's performance in meeting the health needs of Ghanaians, has since its inception in 2003, taken a number of initiatives. These include the free maternal health care introduced in 2008, a health insurance claims processing center established in 2010, introduction of clinical audit in 2010, creation of a consolidated premium account in 2011 and introduction of the national health insurance call center in 2012 [23]. The Authority also introduced biometric identification cards in 2014 to improve client identification and efficient delivery of services [24].

The National Health Insurance Scheme was designed to be pro-poor [20]. In practice, however, most subscribers to the scheme are people in the upper wealth quintile, as the poor and vulnerable including women in their reproductive years are rather less likely to subscribe to the scheme. The present study therefore sought to examine the determinants of health insurance ownership among women of reproductive age in Ghana with data from the 2014 Ghana Demographic and Health Survey. Several studies have investigated the influence of health insurance on other issues including utilisation of maternal health care services and medical out-of-pocket expenses [13, 22, 25-29].

Much attention has, however, not been paid to the background factors which influence subscription to the scheme. Even though Kumi-Kyereme and Amo-Adjei [30] examined factors influencing health insurance subscription in Ghana using data from the 2008 Ghana Demographic and Health Survey (GDHS), the authors focused mainly on spatial location and household wealth as principal determinants. The present study, however, examines the effects of all background characteristics on health insurance subscription and also compares the results to the study conducted by Kumi-Kyereme and Amo-Adjei [30] to identify variations in the factors influencing subscription in the 2008 and 2014 GDHS.

\section{Methods}

\section{Source of data}

The study made use of data from the female data file of the 2014 GDHS. The GDHS is a nationwide survey which covers all ten regions and is conducted every five years. The survey is carried out by the Ghana Statistical Service and the Ghana Health Service with ICF International providing technical support for the survey through MEASURE DHS. The GDHS focuses on child and maternal health and is designed to provide adequate data to monitor the population and health situation in Ghana. The survey gathers data on various demographic and health issues including fertility, contraceptive use, 
child health, nutrition, malaria, HIV and AIDS, family planning, health insurance and maternal health; antenatal care, delivery care and post-natal care. In the 2014 version 9396 women between the ages 15 and 49 were interviewed from 12,831 households covering 427 clusters throughout the country. The survey had a response rate of $97 \%$ [31]. Permission to use the data set was given by the MEASURE DHS following the assessment of a concept note.

\section{Analysis}

The dependent variable employed for this study was ownership of NHIS. The dependent variable was coded $1=$ "Yes" and $0=$ "No" since it was dichotomous. A discrete choice model was employed to show how the independent variables correlated with the dependent variable. Specifically, the binary logistic regression was employed since it allows the predictions on a mixture of continuous and categorical variables, given that this technique is more appropriate for dichotomous variables. A key assumption underlying the binary logistic regression model is that the dependent variable should be dichotomous in nature and the data should not have any outlier. The formulae underpinning the model is given as;

Let $\mathrm{Y}$ be a dichotomous variable which is defined as

$$
\begin{aligned}
& Y=\left\{\begin{array}{c}
1 \text { for subscribers } \\
0 \text { for non-subscribers }
\end{array}\right. \\
& \text { and } \mathrm{p}=\operatorname{Pr}\left(\mathrm{Y}=1 \mid \mathrm{X}_{1}, \ldots, \mathrm{X}_{\mathrm{k}}\right) \text {. } \\
& \mathrm{p}=\frac{1}{1+\exp \left[-\left(\beta_{0}+\beta_{1} \mathrm{X}_{1}+\beta_{2} \mathrm{X}_{2}+\ldots+\beta_{\mathrm{k}} \mathrm{X}_{\mathrm{k}}\right)\right]} \\
& \text { and } \hat{p}=\frac{1}{1+\exp \left[-\left(\hat{\beta}_{0}+\hat{\beta}_{1} X_{1}+\hat{\beta}_{2} X_{2}+\ldots+\hat{\beta}_{k} X_{k}\right)\right]} \\
& \text { Note: With no predictors, } \hat{\mathrm{p}}=\frac{\sum_{\mathrm{i}=1}^{\mathrm{n}} \mathrm{Y}_{\mathrm{i}}}{\mathrm{n}}=\overline{\mathrm{Y}}
\end{aligned}
$$

Nine independent variables were used for the study; Maternal age, marital status, educational level, residence, wealth quintile, ethnicity, occupation, parity (Birth order) and region of residence. Maternal age was categorised into, $15-19,20-24,25-29,20-34,35-39,40-44$, and 45-49. Marital status was recoded as single (never married, widowed, divorced, not living together), married and cohabitation (living together). Education level was classified into four categories: No education, primary education, secondary education and higher education.

Type of residence was coded as urban and rural while wealth quintile was categorised as poorest, poorer, middle, richer and richest. Ethnicity was recoded as Akan, Ga/Dangme, Ewe, Guan, Mole-Dagbani, Grusi, Gurma and Other. Occupation was captured as not working and working. Parity (birth order) was categorised as zero birth, one birth, two births, three births and four births or more. Region of residence was re - coded to capture the general ecological zones as follows: Northern, Upper West and Upper East regions were re - coded as the 'Savannah zone'; the Brong - Ahafo, Ashanti and Eastern regions were designated as the 'forest zone'; while the Western, Central, Greater Accra and Volta regions were coded as the 'coastal zone'. Religion was captured as Catholic, Anglican, Methodist, Presbyterian, Pentecostal/ charismatic, Other Christian, Islam, African Traditional/ spiritual and other. Survey weights, which are typical of nationally representative studies, were factored into both inferential and descriptive analyses conducted. The weights helped to offset the challenges of under and over sampling usually associated with national surveys. All analyses were conducted with STATA, version 13.

\section{Results}

Table 1 presents respondents who were registered under the NHIS, based on various socio-demographic characteristics which comprised residence, ecological zone, age, ethnicity, occupation, education, religion, wealth status, marital status, and parity. In terms of religion, it was observed that less than half of the women in both rural $(47.5 \%)$ and urban (47.3\%) settlements had health insurance. While majority of women in the forest zone (64.2\%) had insurance, less than $50 \%$ of their counterparts in the coastal $(37 \%)$ and savannah $(39.5 \%)$ were NHIS subscribers. Less than half of the respondents in their late teens $(42 \%)$, early thirties $(42.7 \%)$, and late forties (41.2 \%) also had insurance.

It was observed that below $50 \%$ of respondents who were $\mathrm{Ga} /$ Dangmes (29.6\%), Ewes (38.6 \%), Gurmas (27.6\%), and other (44.1\%) actually owned health insurance. Respondents with no education also had the lowest insurance ownership (38.6\%). It was also realised that health insurance subscription was higher for those working than those who were not working at the time of the survey. While over $50 \%$ of married women were having health insurance, less than half of those single and cohabiting were subscribed to the scheme. African Traditionalists were the least of the respondents who owned health insurance. It was only respondents in the 'Richer' and 'Richest' wealth categories that majority had health insurance. In terms of parity, women who had never given birth were the least to have health insurance. Overall, $47.4 \%$ of the weighted sample was registered under the scheme. It was observed from the Chi-square tests conducted that in exception of occupation, all the other background characteristics had significant associations with health insurance ownership.

Table 2 presents results of the Binary logistic regression of NHIS subscription among the women surveyed. 
Table 1 Insurance coverage and background characteristics

\begin{tabular}{|c|c|c|c|c|}
\hline Variable & Correlates & $N=9363$ & Proportion registered & $P$ value \\
\hline \multirow[t]{2}{*}{ Residence } & Urban & 789 & 47.48 & \multirow[t]{2}{*}{$0.050^{*}$} \\
\hline & Rural & 724 & 47.25 & \\
\hline \multirow[t]{3}{*}{ Ecological Zone } & Coastal zone & 616 & 36.97 & \multirow[t]{3}{*}{$0.000^{*}$} \\
\hline & Forest zone & 763 & 64.18 & \\
\hline & Savannah zone & 133 & 39.46 & \\
\hline \multirow[t]{7}{*}{ Age } & $15-19$ & 250 & 41.99 & \multirow[t]{7}{*}{$0.000^{*}$} \\
\hline & $20-24$ & 303 & 49.58 & \\
\hline & $25-29$ & 247 & 50.01 & \\
\hline & $30-34$ & 179 & 42.75 & \\
\hline & $35-39$ & 209 & 52.66 & \\
\hline & $40-44$ & 200 & 52.66 & \\
\hline & $45-49$ & 125 & 41.21 & \\
\hline \multirow[t]{9}{*}{ Ethnicity } & Akan & 928 & 52.80 & \multirow[t]{9}{*}{$0.000^{*}$} \\
\hline & Ga/dangme & 78 & 29.55 & \\
\hline & Ewe & 150 & 38.55 & \\
\hline & Guan & 31 & 45.08 & \\
\hline & Mole-Dagbani & 193 & 51.32 & \\
\hline & Grusi & 35 & 54.34 & \\
\hline & Gurma & 52 & 27.59 & \\
\hline & Mande & 20 & 76.18 & \\
\hline & Other & 27 & 44.10 & \\
\hline \multirow[t]{2}{*}{ Occupation } & Not working & 330 & 45.01 & \multirow[t]{2}{*}{0.36} \\
\hline & Working & 1181 & 47.34 & \\
\hline \multirow[t]{4}{*}{ Education } & No education & 240 & 38.56 & \multirow[t]{4}{*}{$0.000^{*}$} \\
\hline & Primary & 284 & 43.09 & \\
\hline & Secondary & 922 & 51.83 & \\
\hline & Higher & 68 & 50.15 & \\
\hline \multirow[t]{9}{*}{ Religion } & Catholic & 147 & 56.08 & \multirow[t]{9}{*}{$0.000^{*}$} \\
\hline & Anglican & 17 & 59.77 & \\
\hline & Methodist & 125 & 58.91 & \\
\hline & Presbyterian & 99 & 54.59 & \\
\hline & Pentecostal/charismatic & 679 & 47.21 & \\
\hline & Other Christian & 212 & 41.84 & \\
\hline & Islam & 182 & 48.63 & \\
\hline & African Traditional/spiritual & 13 & 17.60 & \\
\hline & Other & 0 & 0 & \\
\hline \multirow[t]{5}{*}{ Wealth status } & Poorest & 195 & 40.16 & \multirow[t]{5}{*}{$0.001^{*}$} \\
\hline & Poorer & 274 & 43.64 & \\
\hline & Middle & 348 & 48.44 & \\
\hline & Richer & 379 & 51.80 & \\
\hline & Richest & 318 & 50.24 & \\
\hline
\end{tabular}


Table 1 Insurance coverage and background characteristics (Continued)

\begin{tabular}{llll}
\hline Marital status & Single & 721 & 45.24 \\
& Married & 540 & 50.06 \\
& Cohabitation & 253 & 48.31 \\
Parity & No birth & 465 & 43.26 \\
& One birth & 202 & 50.24 \\
& Two births & 204 & 52.53 \\
& Three births & 185 & 50.76 \\
& Four births or more & 457 & 47.39 \\
\hline
\end{tabular}

Source: GDHS 2014

Proportion registered* mean the proportion of women who had registered under the National Health Insurance Scheme (NHIS)

The results reveal significant effects of wealth status (richer, richest), age (45-49), ecological zone (forest zone, savannah), religion (Pentecostal/charismatic, other Christian, African traditionalist/spiritualist, no religion), ethnicity (Ga/Dangme), education, marital status (married), and parity on subscription. Women in the rural areas were more likely to own health insurance compared with their colleagues in urban areas. Those in the 'richer' wealth quintile were found to be $170 \%$ more likely to register with the NHIS than those in the 'poorest' wealth quintile. Respondents in the forest $(\mathrm{OR}=2.863, \mathrm{CI}=2.393-3.426)$ and savannah $(\mathrm{OR}=2.167, \mathrm{CI}=1.580-2.972)$ zones also had higher probabilities of owning health insurance compared with women in the coastal zone. Regarding religion, it was observed that only Anglicans $(\mathrm{OR}=1.231$, $\mathrm{CI}=0.515-2.944)$ and Methodists $(\mathrm{OR}=1.010, \mathrm{CI}=0.692-$ 1.475) were more likely to own health insurance than Catholics. Irrespective of the number of births, it was observed that respondents who had ever given birth were all at least $140 \%$ more likely to own health insurance compared with those who had never given birth (Table 2).

\section{Discussion}

Even though the overall weighted sample registered under the scheme was slightly higher than what was reported by Kumi-Kyereme and Amo-Adjei [30] (40.2 \%) it does not refute the argument made by Amu [32] that the NHIS has failed to cover $100 \%$ of the Ghanaian population after five years as stipulated in the objectives of the scheme upon its creation in 2003. The less than $50 \%$ NHIS ownership observed within the weighted sample may be due to the fact that people are unable to afford the cost of subscribing to the scheme as opined by Amu [32]. Boateng and Awunyor-Vitor [33] also argued that some people usually consider the premium for subscribing to the NHIS as too expensive and this serves as a barrier to their ownership of the scheme. This is particularly so for persons who pay annual premiums on the scheme; eg. Informal sector workers. The fact that 'Richer' and 'Richest' wealth quintiles were the only categories within wealth status where majority were
NHIS subscribers thus underscores the role of wealth in influencing the ability of people to subscribe to health insurance as mentioned by Kumi-Kyereme and AmoAdjei [30]. It therefore clearly justifies the inability of majority of women in the lower wealth quintiles to subscribe to the scheme.

The issue of expensiveness of yearly premium for subscribing to the NHIS was one of the reasons in 2008, prior to the general elections in Ghana, and still dominating debates in the country, a one-time premium payment on the scheme became a major issue of debate among the various contesting political parties, with the National Democratic Congress (NDC) proposing its adoption. With a one-time NHIS premium system, subscribers will be required to pay premium only once in their entire life time [34]. The major argument against this policy by opposing political parties, including the New Patriotic Party (NPP), is, however, the fact that a one-time premium would mean subscribers paying huge sums of money, which in itself, defeats the purpose of introducing such a policy in the first place; to reduce the cost of paying for the scheme by subscribers.

The findings where $40.2 \%$ were subscribed to the scheme, may also be attributed to delays - as a result of long queues - which characterise registration/renewal of NHIS membership and utilisation of health services with insurance or dissatisfaction with quality of services received from the scheme regarding registration/renewal and health care use $[10,35]$. The fact that African traditionalists were the least to own health insurance may be attributable to the fact that they largely believe in the use of herbal and/or African traditional medicine [36] at the expense of orthodox ones compared to people with other religious perspectives.

The fact that level of education predicted health insurance subscription is an indication that educational attainment cannot be ruled out when decisions regarding utilisation of health care services are concerned. It was thus obvious to note from the study that at least half of all women with secondary and higher levels of education were subscribed to the NHIS [37]. Amu [32] noted in this 
Table 2 Binary logistic regression on ownership of health insurance

\begin{tabular}{|c|c|c|}
\hline Independent variable & Odds ratio & $95 \%$ confidence interval \\
\hline \multicolumn{3}{|l|}{ Residence } \\
\hline Urban & Ref & Ref \\
\hline Rural & 1.163 & $0.950-1.423$ \\
\hline \multicolumn{3}{|l|}{ Wealth status } \\
\hline Poorest & Ref & Ref \\
\hline Poorer & 1.058 & $0.811-1.381$ \\
\hline Middle & 1.235 & $0.925-1.649$ \\
\hline Richer & $1.700^{* *}$ & $1.202-2.318$ \\
\hline Richest & $1.445^{*}$ & $0.987-2.117$ \\
\hline \multicolumn{3}{|l|}{ Age } \\
\hline $15-19$ & Ref & Ref \\
\hline $20-24$ & 1.045 & $0.805-1.356$ \\
\hline $25-29$ & 0.991 & $0.715-1.374$ \\
\hline $30-35$ & 0.800 & $0.551-1.161$ \\
\hline $35-39$ & 1.044 & $0.705-1.549$ \\
\hline $40-44$ & 0.987 & $0.654-1.489$ \\
\hline $45-49$ & $0.644^{* *}$ & $0.419-0.993$ \\
\hline \multicolumn{3}{|l|}{ Ecological zone } \\
\hline Coastal zone & Ref & Ref \\
\hline Forest zone & $2.863^{* * *}$ & $2.393-3.426$ \\
\hline Savannah & $2.167^{* * *}$ & $1.580-2.972$ \\
\hline \multicolumn{3}{|l|}{ Religion } \\
\hline Catholic & Ref & Ref \\
\hline Anglican & 1.231 & $0.515-2.944$ \\
\hline Methodist & 1.010 & $0.692-1.475$ \\
\hline Presbyterian & 0.859 & $0.576-1.282$ \\
\hline Pentecostal/charismatic & $0.747^{*}$ & $0.577-0.968$ \\
\hline Other Christian & $0.571^{* * *}$ & $0.421-0.775$ \\
\hline Islam & 0.862 & $0.630-1.179$ \\
\hline Traditionalist/spiritualist & $0.252^{* * *}$ & $0.146-0.437$ \\
\hline No religion & $0.375^{* * *}$ & $0.237-0.595$ \\
\hline Other & 1 & \\
\hline \multicolumn{3}{|l|}{ Ethnicity } \\
\hline Akan & Ref & Ref \\
\hline $\mathrm{Ga} /$ dangme & $0.548^{* * *}$ & $0.392-0.762$ \\
\hline Ewe & 1.110 & $0.880-1.454$ \\
\hline Guan & 0.651 & $0.401-1.057$ \\
\hline Mole-Dagbani & 1.248 & $0.909-1.712$ \\
\hline Grusi & 1.852 & $1.112-3.062$ \\
\hline Gurma & 0.470 & $0.319-0.692$ \\
\hline Mande & 4.382 & $1.783-10.733$ \\
\hline Other & 1.018 & $0.570-1.817$ \\
\hline
\end{tabular}

Table 2 Binary logistic regression on ownership of health insurance (Continued)

\begin{tabular}{lll}
\hline Education & & \\
No education & Ref & Ref \\
Primary & $1.341^{*}$ & $1.054-1.707$ \\
Secondary & $1.999^{* * *}$ & $1.578-2.503$ \\
Higher & $1.702^{*}$ & $1.030-2.814$ \\
Occupation & & \\
Not Working & Ref & Ref \\
Working & 0.977 & $0.802-1.191$ \\
Marital status & & \\
Single & Ref & Ref \\
Married & $1.396^{* *}$ & $1.123-1.735$ \\
Cohabitation & 1.012 & $0.792-1.296$ \\
Parity & & \\
Zero birth & Ref & Ref \\
One birth & $1.570^{* *}$ & $1.190-2.073$ \\
Two births & $1.840^{* * *}$ & $1.340-2.525$ \\
Three births & $1.436^{*}$ & $1.010-2.040$ \\
Four births or more & $1.652^{* *}$ & $1.167-2.360$ \\
\hline
\end{tabular}

Source: GDHS $2014{ }^{*} P<0.05{ }^{* *} p<0.01{ }^{* * *} p<0.001$

regard that people with high levels of education may have a higher outlook with regards to the necessity of being ready for any unforeseen health challenges and as such decide to own health insurance, as opposed to those with lower or no level of education who may not realise the level of threat that will be posed to their health and life if they are not prepared financially for any unforeseen health challenges but they eventually occur [38].

As observed in our study, a woman's age does inform her decisions regarding health insurance subscription. Age influences perception of susceptibility to health conditions and the seriousness attached such conditions [39]. The level of susceptibility then results in decisions to either subscribe to health insurance in order to be ready for unforeseen health challenges or not to do so [38]. Women in rural areas being more likely to subscribe to health insurance than women in urban areas is an indication of the higher need for health care services documented to exist in rural areas than in urban areas [40-42]. Thus, women in the rural areas were more likely to subscribe to the health insurance so as to be able to afford health care in times of need, as they may not be able to afford health care out-of-pocket if they fall sick [43].

Our findings regarding ecological zone confirm those found by Kumi-Kyereme and Amo-Adjei [30] in which the authors posited that the highest percentage of women subscribed to the NHIS was in the forest zone while the least was from the Coastal zone. The fact that 
women with zero parity had the least rate of subscription to the NHIS may be because they did not require pregnancy and childbirth services which are services that make most women in their reproductive age to Ghana to subscribe to the NHIS as they are exempted from the payment of premiums [44].

\section{Conclusions}

We found that education, wealth status, age, religion, birth parity, marriage and ecological zone predict health insurance subscription among women in their reproductive ages in Ghana. Urban dwellers, women who have never given birth, those with no or low levels of education, African traditionalists and the poor were women who largely did not subscribe to the scheme. The NHIA should therefore carry out more education than they are currently doing, in association with the National Commission for Civic Education and the Information Services Department to recruit more of these people unto the scheme. The indigent for instance should be made aware through these educational campaigns that subscription to the NHIS for them is without any charges, which will encourage them to subscribe.

\section{Competing interests}

The authors declare that they have no competing interests.

\section{Authors' contributions}

HA and KSD conceived the study. KSD designed and performed the analysis. HA drafted and edited the manuscript. Both authors proof-read the final manuscript and approved it.

\section{Acknowledgements}

We wish to thank MEASURE DHS for granting us permission to use their data for our analysis.

Received: 11 March 2016 Accepted: 7 June 2016

Published online: 21 June 2016

\section{References}

1. Carman KG, Eibner C. Changes in health insurance enrollment since 2013: evidence from the RAND health reform opinion study. Washington DC: RAND Corporation; 2014.

2. Lagomarsino G, Garabrant A, Adyas A, Muga R, Otoo N. Moving towards universal health coverage: health insurance reforms in nine developing countries in Africa and Asia. Lancet. 2012;380:933-43.

3. Van Doorslaer E, O'donnell O, Rannan-Eliya RP, Somanathan A, Adhikari SR, Garg C, et al. Effect of payments for health care on poverty estimates in 11 countries in Asia: an analysis of household survey data. Lancet. 2006;368:1357-64.

4. Palmer R, Weiss BD. Relationship between health care costs and very low literacy skills in a medically needy and indigent medicaid population. J Am Board Fam Pract. 2004:17:44-7.

5. Sarpong N, Loag W, Fobil J, Meyer CG, Adu-Sarkodie Y, May J, Schwarz NG. National health insurance coverage and socio-economic status in a rural district of Ghana. Tropical Med Int Health. 2010;15(2):191-7. doi:10.1111/j.1365-3156.2009. 02439.x.

6. Leive A, Xu K. Coping with out-of-pocket health payments: empirical evidence from 15 African countries. Bull World Health Organ. 2008;86:849-56.

7. World Health Organization. Sustainable health financing, universal coverage and social health insurance. World Health Assembly Resolution. 58. Geneva: WHO; 2005.

8. Aggrey M, Appiah SCY. The influence of clients' perceived quality on health care utilisation. Int J Innov Appl Stud. 2014:9(2):918-24.

9. Wagstaff A. Soc Health Insur Reexamined Health Econ. 2010;19:503-17.
10. Mulupi S, Kirigia D, Chuma J. Community perceptions of health insurance and their preferred design features: implications for the design of universal health coverage reforms in Kenya. BMC Health Serv Res. 2013;13:474. doi:10.1186/1472-6963-13-474.

11. Lekashingo LD. Exploring the effects of user fees, quality of care and utilisation of health services on enrolment in community health fund, Bagamoyo District, Tanzania. Master's thesis. Dar es Salaam: Muhimbili University of Health and Allied Sciences; 2012.

12. Republic of Kenya. Kenya national health accounts 2009/2010. Nairobi: Ministry of Medical Services and Ministry of Public Health and Sanitation; 2011.

13. Mensah J. The impact of national health insurance scheme on health delivery in Brong Ahafo Region: a case study on Jaman North, Master's thesis. Kumasi: Kwame Nkrumah University of Science and Technology; 2011.

14. Unumeri GO. Perception and conflict. Lagos: National Open University of Nigeria; 2009.

15. Chaudhury A, Roy K. Changes in out-of-pocket payments for health care in Vietnam and its impact on equity in payments, 1992-2002. Health Policy. 2008;88:38-48.

16. Currie J, Madrian B. Health, health insurance and the labor market. Handbook of Labor Economics. Amsterdam: Elsevier-North Holland; 2005.

17. Xu K, Evans DB, Kawabata K, Zeramdini R, Klavus J, Murray CJ. Household catastrophic health expenditure: a multicounty analysis. Lancet. 2003;362:111-7.

18. Government of Ghana. National health insurance act, 2003 (Act 650). Accra: Ghana Publishing Corporation; 2003.

19. Government of Ghana. National health insurance regulations, 2004 (L.I. 1809). Accra: Ghana Publishing Corporation; 2004.

20. Universal Access to Health Care Campaign Coalition. Ten years of the national health insurance scheme in Ghana: a civil society perspective on its successes and failures. Accra: Universal Access to Health Care Campaign Coalition; 2013.

21. Boakye-Frimpong $P$. The quest for equity in the provision of health care in Ghana. Afr Rev Econ Finance. 2013;4(2):254-72.

22. Blanchet NJ, Fink G, Osei-Akoto I. The effect of Ghana's national health insurance scheme on health care utilisation. Ghana Med J. 2012;46(2):76-84

23. National Health Insurance Authority (NHIA). 2012 annual report. Accra: NHIA; 2012.

24. National Health Insurance Authority (NHIA). Functions of the authority. 2015 Accessed 17 Jan 2016 from http://www.nhis.gov.gh/nhia.aspx.

25. Brugiavini A, Pace N. Extending health insurance in Ghana: effects of the National Health Insurance Scheme on maternity care. Heal Econ Rev. 2016;6:7.

26. Dapatem DA. Nine million Ghanaians use health insurance. 2013. Accessed 16 Nov 2015 from http://www.graphic.com.gh/.

27. Adjei AM. The impact of national health insurance on community pharmacies: a case study of the Western Region of Ghana, Master's thesis. Kumasi: Kwame Nkrumah University of Science and Technology; 2012.

28. Ghana Health Service. An evaluation of the effects of the national health insurance scheme in Ghana. Bethesda: Abt Associates Inc. and Ghana Health Service; 2009.

29. Aikins M, Okan G. Effects of health insurance on utilisation and cost of health service. Accra: JSA consultants Ltd; 2005.

30. Kumi-Kyereme A, Amo-Adjei J. Effects of spatial location and household wealth on health insurance subscription among women in Ghana. BMC Health Serv Res. 2013;13:221. doi:10.1186/1472-6963-13-221.

31. Ghana Statistical Service (GSS), Ghana Health Service (GHS), ICF International. Ghana demographic and health survey 2014: key indicators report. Maryland: GSS, GHS and ICF; 2015.

32. Amu H. Health insurance subscription in the Cape Coast Metropolis, Unpublished Master's thesis. Cape Coast: University of Cape Coast; 2015.

33. Boateng D, Awunyor-Vitor D. Health insurance in Ghana: evaluation of policy holders' perceptions and factors influencing policy renewal in the Volta Region. Int J Equity Health. 2013;12:50. doi:10.1186/1475-9276-12-50.

34. Allotey A. Financing health care in Ghana: Is one-time insurance premium the answer? 2012. Accessed 16 Jan 2016.from http://www.myjoyonline.com/ ghana-news/opinion.php.

35. Jehu-Appiah C, Aryeetey G, Agyepong I, Spaan E, Baltussen R. Household perceptions and their implications for enrolment in the national health insurance scheme in Ghana. Health Policy Plan. 2012;27:222-33.

36. Adjei B. Utilisation of traditional herbal medicine and its role in health care delivery in Ghana: the case of wassa Amenfi west district, Master's thesis. Kumasi: Kwame Nkrumah University of Science and Technology; 2013. 
37. Andersen RM. National health surveys and the behavioural model of health services use. Med Care. 2008;46(7):647-53.

38. Mhere F. Health insurance determinants in Zimbabwe: case of Gweru urban. J Appl Bus Econ. 2013;14(2):62-79.

39. Karen G, Rimer BK, Viswanath K. Health behaviour and health education: theory, research and practice. 4th ed. San Francisco: Jossey-Bass; 2008.

40. Alkire S, Chatterjee M, Conconi A, Suman S, Vaz A. Poverty in Rural and Urban Areas Direct comparisons using the global MPI 2014. Oxford: Oxford Poverty \& Human Development Initiative; 2014.

41. World Bank. Agriculture and poverty reduction. Washington DC: World Bank; 2013.

42. O'Hare W. Poverty is a persistent reality for many rural children in U.S. Washington DC: Population Reference Bureau; 2014.

43. Duku SKO, Fenenga CJ, Alhassan RK, Nketiah-Amponsah E. Rural-urban differences in the determinants of enrolment in health insurance in Ghana. Paris: International union for the scientific study of population; 2013.

44. National Health Insurance Authority (NHIA). 2010 annual report. Accra: NHIA; 2010.

\section{Submit your manuscript to a SpringerOpen ${ }^{\odot}$ journal and benefit from:}

- Convenient online submission

- Rigorous peer review

- Immediate publication on acceptance

- Open access: articles freely available online

- High visibility within the field

- Retaining the copyright to your article

Submit your next manuscript at $\boldsymbol{s p r i n g e r o p e n . c o m ~}$ 